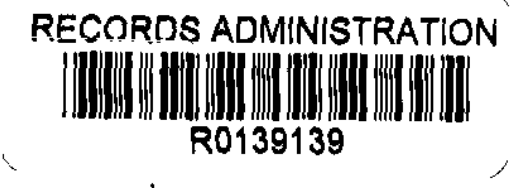

DP-1551

\title{
REAL TIME QUALITY CONTROL OF METEOROLOGICAL DATA USED IN SRP'S EMERGENCY RESPONSE SYSTEM
}

\author{
M. M. PENDERGAST
}

E. I. du Pont de Nemours \& Co. Savannah River Laboratory Aiken, SC 29808 
DISCLAIMER

This report was prepared as an account of work sponsored by the United Statea Government. Noither the United States nor the United States Depertment of Energy, nor any of their employees, make any werrenty, ex press or implied, of assumat any legal lisbility or responsibility for the accuracy, complotenoes, or usofulness of any information, apparatus, product, or procest disclomed, or represents that its use would not infringe privetely owned rights. Reference heroin to any zpecific commerciel pro. duct, process, or service by trade name, mark, manufacturar, or otherwize, does not necessarily constitute or imply its endorsement, recommendation. or favoring by the Unlted States Government or any egency thereof. The viows and opinions of authors expreswed heroln do not necessarily state or reflect thow of the United States Government or any agency thereof.

Printed in the United States of America Available from

National Tochnical Information Service

U. S. Department of Commerce 5285 Port Roval Road Springfield, Virginia 22161

Price: Printed Copy A02; Microfiche A01 


\section{REAL TIME QUALITY CONTROL OF METEOROLOGICAL DATA USED IN SRP'S EMERGENCY RESPONSE SYSTEM}

by

M. M. Pendergast

Approved by

Todd V. Crawford, Research Manager

Environmental Transport Division

Publication Date: May 1980

Issued by E. I. du Pont de Nemours \& Co. Savannah River Laboratory

Aiken, SC 29808

PREPARED FOR THE U. S. DEPARTMENT OF ENERGY UNDER CONTRACT OE.AC09-76SR00001 
The Savannah River Laboratory's WIND minicomputer system allows quick and accurate assessment of an accidental release at the Savannah River Plant using data from eight meteorological towers. The accuracy of the assessment is largely determined by the accuracy of the meteorological data; therefore quality control is important in an emergency response system. Real-time quality control of this data will be added to the WIND system to automatically identify inaccurate data. Currently, the system averages the measurements from the towers to minimize the influence of inaccurate data being used in calculations. The computer code used in the real-time quality control has been previously used to identify inaccurate measurements from the archived tower data. 


\section{CONTENTS}

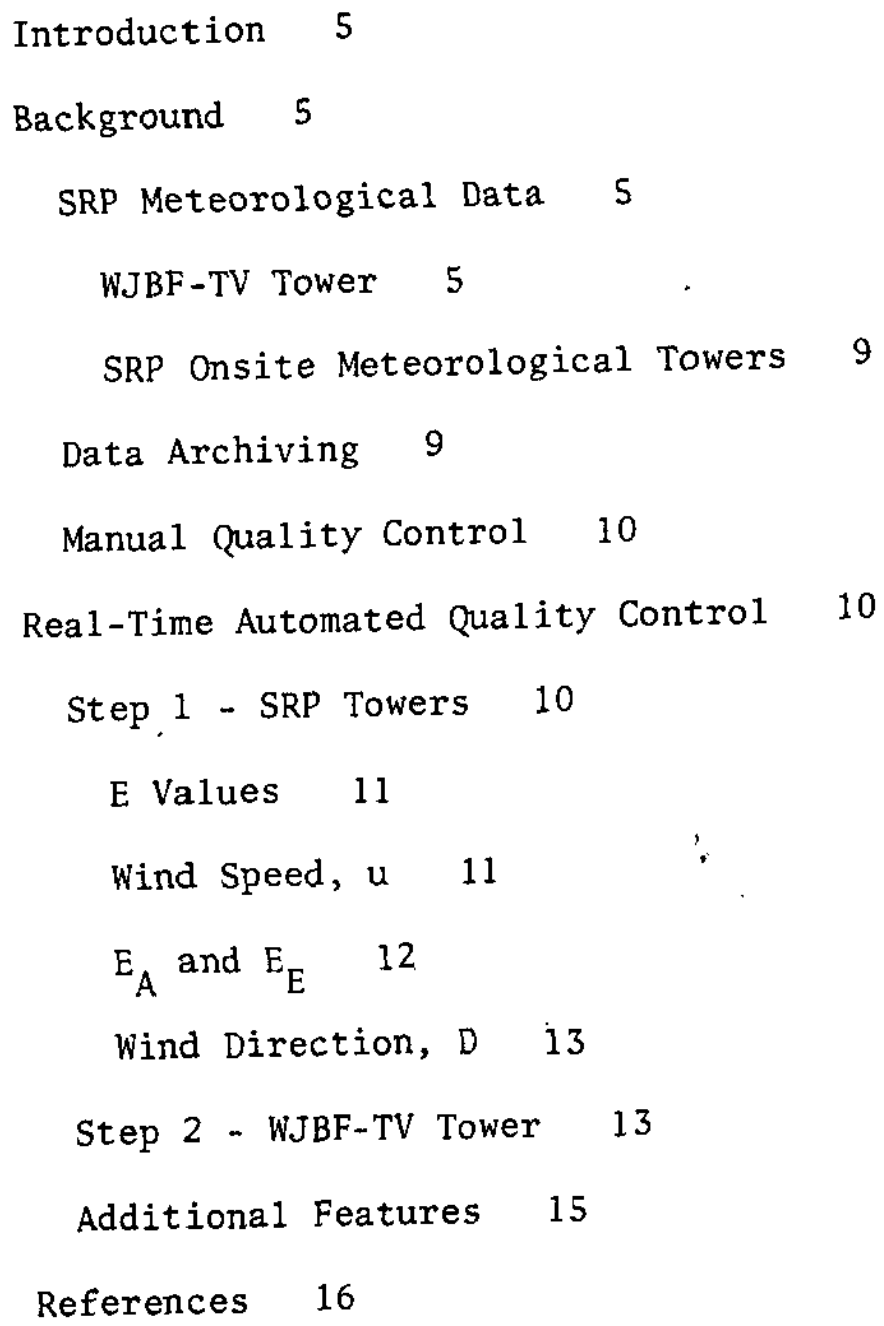




\section{LIST OF TABLES}

1 Power Law Exponents for $u, \sigma_{A}$, and $\sigma_{E}$ at SRP 14

2 Linear Change of Temperature and Wind Direction at SRP After Safety Guide 23 and Pasquill [1964] 15

\section{LIST OF FIGURES}

1 Data Sources for SRP 6

2 Location of Meteorological Instrumentation at the WJBF-TV Transmitter Site 7

3 Repositioned Meteorological Instrumentation at the WJBF-TV Transmitter Site 8 
REAL TIME QUALITY CONTROL OF METEOROLOGICAL DATA USED IN SRP'S EMERGENCY RESPONSE SYSTEM

\section{INTRODUCTION}

One of the major problems associated with any nuclear accident (such as that occurring at Three-Mile Island Nuclear Power Plant) is the ability to assess the consequence of an accident quickly and accurately. Modern computer systems provide the computational power, speed, and reliability to provide such timely assessments provided that accurate meteorological data are available. Real-time quality control of the meteorological data is therefore an important part of any emergency response system.

SRP has eight meteorological towers monitored by a PDP-11/40* minicomputer called the WIND (Weather Information and Display) system. The WIND system is used to assess a routine or an accidental release to the environment. The meteorological data are permanently archived on magnetic tape at 5 -sec intervals and temporarily stored on disks readily accessible by the minicomputer. The computer can provide calculations of relative concentrations in real time using the archived meteorological data.

The major justification of a real-time quality control code is its importance to SRP's emergency response. The real-time quality control code will also be useful as SRP changes its meteorological archiving procedures. In the near future, 15-min average data will be stored instead of the 5 - sec individual values. Quality control will be used for the 15 -min averaged data and erroneous data will be replaced with an appropriate estimate.

\section{BACKGROUND}

\section{SRP Meteorological Data}

\section{WJEF-TV Tower}

A $335-m$ TV tower (Station WJBF-TV), located $30 \mathrm{~km}$ northwest of the geometrical center of SRP, is instrumented with Climet** bivane wind systems and platinum resistance thermometers (Figure 1).

* Product of Digital Equipment Corporation

** Trade Name of Climate Instruments, Sunnyvale, CA 
WJEF TV

$\Delta$

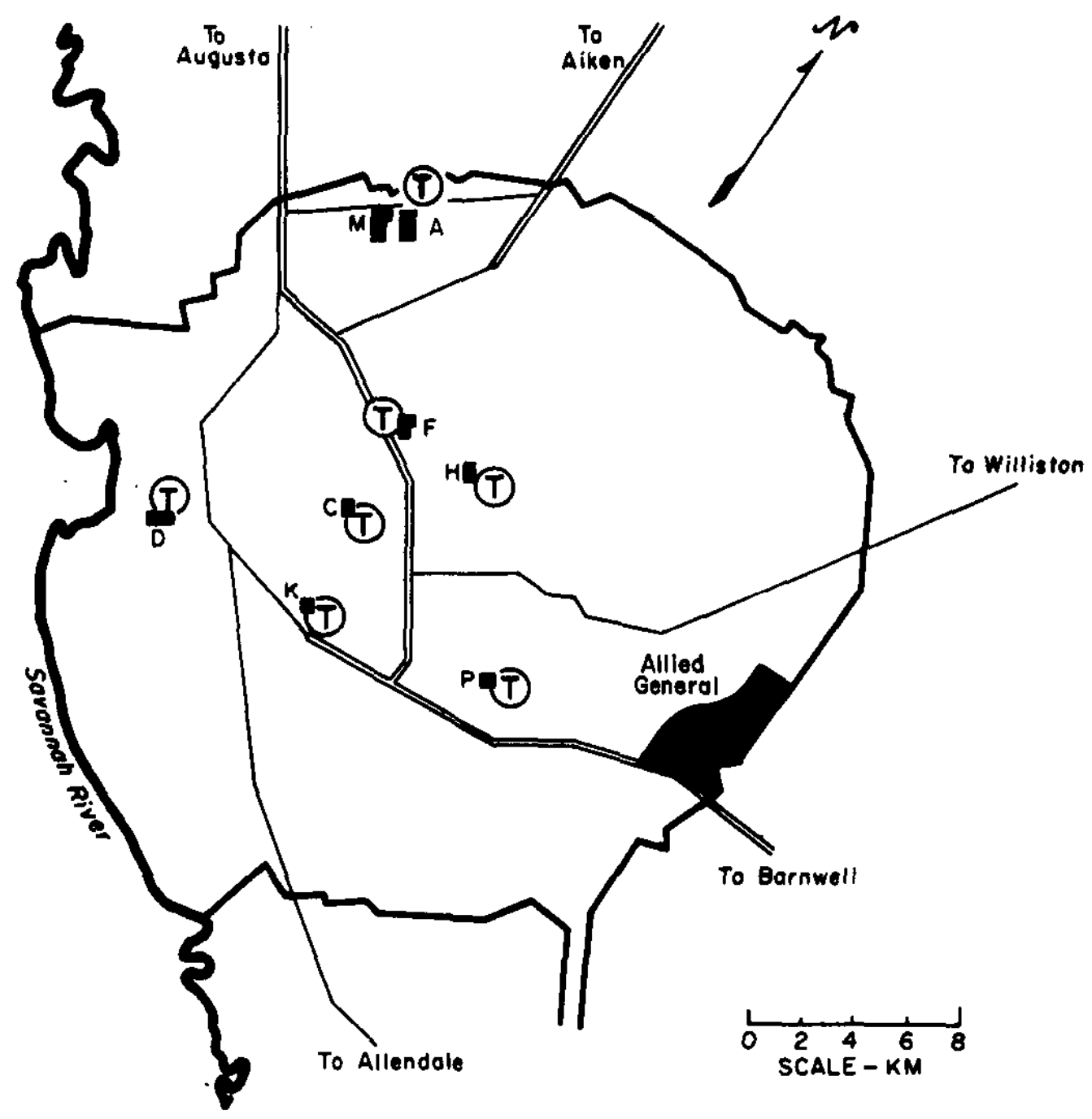

FIGURE 1. The Meteorological Towers Distributed on SRP 
A $10-\mathrm{m}$ tower to collect near-surface data is near the TV tower, but far enough away from the transmitter building so that the air reaching this tower is representative of the surrounding area (Figure 2 ).**

The configurations of tower instruments for routine data collection give 32 channels of meteorological information in addition to date, time, and reference voltages (Figure 3). The 32 channels of data are telemetered over telephone lines to SRL's Weather Center Analysis Laboratory (A-Area in Figure 1).

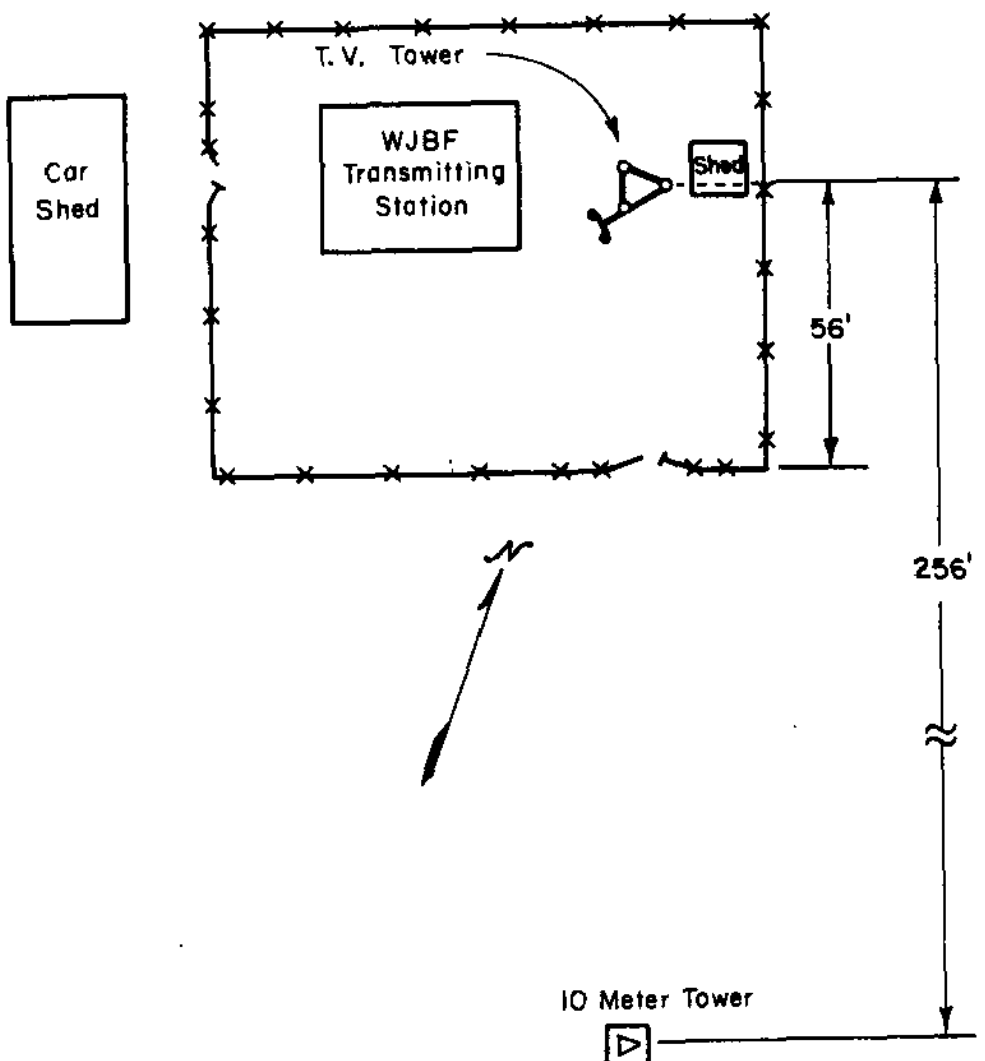

FIGURE 2. Location of Meteorological Instrumentation at the WUBF-TV Transmitter Site

** In 1974 the area surrounding the 10-m tower was covered by $1-m$-tall pine trees. In 1980 the pine trees have grown to a height of $9 \mathrm{~m}$. 

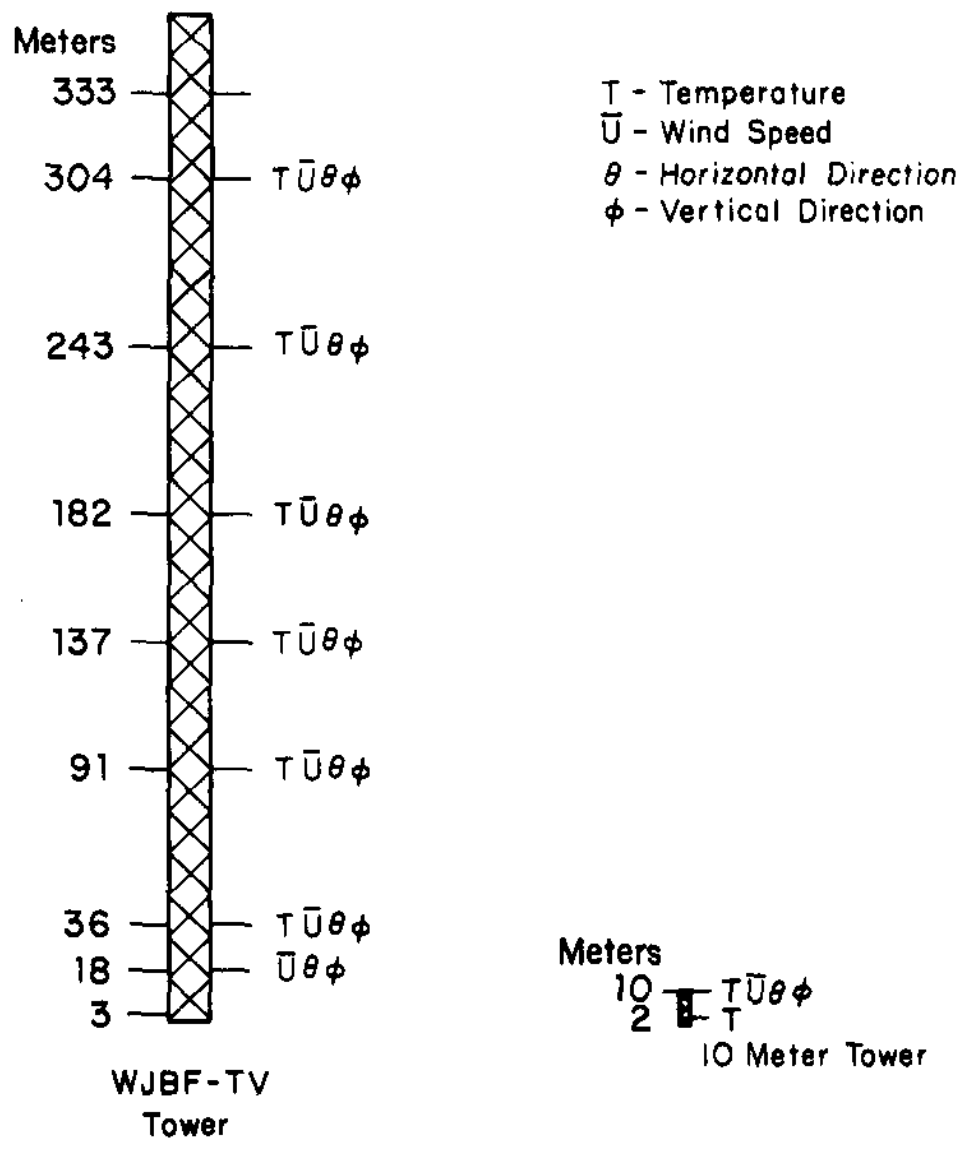

FIGURE 3. Repositioned Meteorological Instrumentation at the WUBF-TV Transmitter Site 
SRP Onsite Meteorological Towers

The SRP production areas have meteorological towers that measure wind direction and speed, and turbulence for use in emergencies (Figure 1). The Vectorvane* instruments to measure wind direction and velocity are mounted $62 \mathrm{~m}$ above the ground to match the height of the major SRP stacks through which effluents are released. The D-Area tower has a wind instrument at $18 \mathrm{~m}$.

The towers located in pine forests about $0.8 \mathrm{~km}$ from the main buildings in the operating areas give data representative of the general landscape of SRP. The towers are positioned where the prevailing winds do not pass over any buildings before reaching them. Twenty-four channe1s of data are recorded in the adjacent area control rooms and telemetered to the Weather Center.

\section{Data Archiving}

The DATA $\operatorname{COM}^{* *}$ acquisition system in the Weather Center (A-Area on Figure 1) is the primary means of archiving all tower data. All data are recorded on magnetic tape in blocks, each consisting of a prescribed number of complete data scans. Each data scan (or record) is preceded by a notation of the year, day, hour, minute, and second. The data acquisition system has the capability of scanning all channels (TV tower and SRP towers) in as little as 0.86 seconds.

Since 1973, the meteorological data have been stored on magnetic tape at 5-sec intervals in a format compatible with SRL's IBM-360/195' computer. The DATA COM acquisition system is also linked to the PDP-11/40 computer, which can store up to two weeks of meteorological data, averaged over a $15 \mathrm{~min}$ period, on disks to make subsequent environmental assessments within a few seconds. Graphics codes are executed to display summaries of archived meteorological data. This computer output makes it possible for an operator to assess the status of all instrumentation quickly and accurately.

* Trademark of Meteorology Research, Inc., Altadena, CA.

* Product of DATA COM, Inc., Fort Walton Beach, FL.

$\dagger$ Product of International Business Machines, Armonk, NY. 


\section{Manual Quality Control}

Manual quality control is necessary because output from the wind and temperature sensors are only collected on magnetic tape. Strip charts are not recorded simultaneously.

Quality control is achieved by routine inspection of data summaries by a meteorologist. These summaries are generated automatically by the PDP-11/40 computer, and hard copies are printed hourly. Examination of these data permits judgments to be made on the acceptability of the data. For example, an intercomparison of wind speeds on the eight SRP towers and seven wind speeds on the WJBF-TV tower will show a fairly large range of values. Some variation of speed is expected as the result of height of measurement and/or spatial separation of towers. Wind speeds that exceed this expected variation are considered to be in error.

Usually, major system malfunctions are obvious to the experienced meteorologist. The challenge is an early detection of such things as an intermittent wiper contact in one of the wind direction units, a burned-out bulb in an anemometer, or a bent bivane tail.

Once malfunctions are detected, maintenance crews are scheduled, provided the problem can be fixed from the ground. More serious problems on the WJBF-TV tower are fixed by hiring tower climbers. On the average, tower climbers are used at a six-month interval.

\section{REAL-TIME AUTOMATED QUALITY CONTROL}

The SRP automated quality control code incorporates the many subjective judgments made by a meteorologist as he examines the data using the information available to him as described above. The computer code is intended to be a basis for realtime quality control until superior methods are developed. The first goal of the quality control code is to obtain a spatial average of each variable of the SRP tower data. The second goal is to use these averages for quality control of the WJBF TV-tower data.

\section{Step 1 - SRP Towers}

The real-time quality control method used for each variable of the data begins by determining a spatial average of that variable and computing the difference between each individual value and the spatial average. If the value which shows the largest difference is greater than an expected variation of the 
variable, E, it is considered to be in error. A new spatial average is calculated excluding the erroneous data, and the process is repeated until all values are found to be within $\pm E$ of the spatial average. The new spatial average is then substituted for the variable considered to be in error. The variables that currently have quality control in this way are wind speed, $u$; wind direction, D; standard deviation of wind azimuth, $\sigma_{A}$; and standard deviation of vertical elevation angle, $\sigma_{E}$.

\section{E Vazues}

The E values are critical to the quality control code. If $E$ is chosen too large, some valid data will be ignored. If $E$ to too large, data will be included which would cause significant errors in an accident assessment.

The expected variations of the four variables, $u, D, \sigma_{A}$, and $\sigma_{E}\left(E_{u}, E_{D}, E_{A}\right.$, and $E_{E}$, respectively) are not constant, but change as functions of meteorological conditions. The functional relationships for selecting $\mathrm{E}$ values have been developed on the basis that it is better to underestimate $E$ values than overestimate them. For this reason, E values are assumed to be equal to the expected standard deviation of the variable. For a normally distributed variable this would imply that about $32 \%$ of the time valid data would be ignored; doubling the value of $E$ would reduce this to $10 \%$.

Wind speed, $u$

The expected variation of wind speed, $E_{u}$, is based upon the assumptions

$$
\begin{aligned}
& \sigma_{\mathrm{w}} \simeq \overline{\mathrm{u}} \bar{\sigma}_{\mathrm{E}}, \text { and } \\
& \sigma_{\mathrm{v}} \simeq \overline{\mathrm{u}} \bar{\sigma}_{\mathrm{A}} \quad[\text { slade, 1968] }
\end{aligned}
$$

where $\sigma_{\mathrm{v}}$ and $\sigma_{\mathrm{w}}$ are the standard deviations of the crosswind and vertical components of the wind. The quantities with an overbar (-) indicate spatial averages of quality-controlled SRP tower data. Furthermore, it is assumed that the standard deviation of the along-wind component of the wind, $\sigma_{u}$, is approximately equal to $1.2 \sigma_{v}$ (Weber et al., 1975). With these assumptions the expected error for the wind speed $E_{u}$ is assumed to be approximated by 


$$
E_{u}=\sqrt{\sigma_{v}^{2}+\sigma_{u}^{2}+\sigma_{w}^{2}} \quad \simeq \sqrt{2.44 \sigma_{v}^{2}+\sigma_{w}^{2}}
$$

Combining equations 1,2 and 3 gives

$$
E_{u}=\sqrt{2.44\left(\bar{u} \bar{\sigma}_{A}\right)^{2}+\left(\bar{u} \bar{\sigma}_{E}\right)^{2}}
$$

where $E_{u}$ and $\bar{u}$ are in $\mathrm{m} / \mathrm{sec}$ and $\bar{\sigma}_{\mathrm{A}}$ and $\bar{\sigma}_{\mathrm{A}}$ are expressed in radians

The value of $E_{u}$ changes slowly with time since a decrease in $\bar{u}$ is often accompanied by a corresponding increase in $\bar{\sigma}_{A}$ and $\bar{\sigma}_{E}$. For this reason, $\bar{u}, \bar{\sigma}_{A}$, and $\bar{\sigma}_{E}$ used in Equations 4 are from the previous time period. Since most quality controlling is done at 15-min intervals, no appreciable error is caused by this procedure.

$E_{A}$ and $E_{E}$

The expected values of $E_{A}$ and $E_{E}$ are based on the results of a study of the variation of $\sigma_{A}$ and $\sigma_{E}$ and their standard deviations [Pendergast, 1976]. The variations of $\sigma_{A}$ and $\sigma_{E}$ were examined as a function of atmospheric stability, sampling period $(\tau)$, and wind speed. For all stability conditions, except very unstable conditions, the standard deviation of $\sigma_{A}$, and hence that of $E_{A}$, can be approximated by

$$
E_{A}=0.00214(\bar{u} \tau)^{0.67}
$$

where $E_{A}$ is in degrees, $\vec{u}$ is in $\mathrm{m} / \mathrm{sec}$, and $\tau$ is in seconds. The corresponding relationship for $E_{E}$ is given by

$$
E_{E}=0.0920(\bar{u} \tau)^{0.47}
$$

During very unstable conditions

$$
E_{E}=E_{A} \simeq 10 \mathrm{deg}
$$

irrespective of wind speed and sampling time. 
Wind Direction, $D$

A first estimate of the expected error in wind direction, ED, is assumed to be given by the spatial average of the qualitycontrolled values of $\sigma_{A}$.

$$
E_{D}^{\prime}=\bar{\sigma}_{A}
$$

During very stable conditions when winds are light, the horizontal wind direction may vary greatly, changing over more than 180 degrees of arc [Pasquil1, 1961]. Diffusion meteorologists call this situation plume meandering. This condition is assumed to apply when $\bar{\sigma}_{E}<\sigma_{E M}$ where $\sigma_{E M}$ is the threshold value of $\sigma_{E}$ below which meandering is likely. At the present time, $\sigma_{E M}$ is assumed to be 2 degrees.

The final value of $E_{D}$ is obtained by adjusting $E_{D}$ to account for plume meandering using an approximation of the form

$$
E_{D}=E_{D} \frac{U_{T}}{\bar{u}}
$$

where $E_{D}$ is the adjusted value of $E_{D}, U_{T}$ is a threshold wind speed above which no meandering is likely to occur, and $\bar{u}$ is the spatial averaged wind speed. A value of $10 \mathrm{~m} / \mathrm{sec}$ has been selected for $\mathrm{U}_{\mathrm{T}}$ based upon a subjective analysis of SRP wind statistics. The adjusted value, $E_{D}$, is further restricted to be less than 30 degrees, which is a threshold value determined by a subjective analysis of SRP wind data.

\section{Step 2 - WJBF-TV Tower}

The spatial average values of $\bar{u}, \bar{D}, \bar{\sigma}_{A}$, and $\bar{\sigma}$ as well as $E_{u}$, $E_{D}, E_{A}$, and $E_{E}$ are used for quality control of the meteorological data collected on the WJBF-TV tower. The methodology is identical to that described above except for one additional procedure. This procedure is to eliminate the dependence upon height of measurement. This is accomplished by first adjusting the value of all observations to a height of $62 \mathrm{~m}$. These adjusted values are then quality controlled as above (changing values as required). The final procedure is to adjust the data back to the original heights. The following sections present the relationship used to adjust the several variables to different heights. The power law profile, 


$$
V_{1}=v_{2}\left(\frac{z_{1}}{z_{2}}\right)^{B} V
$$

is used to adjust $u, \sigma_{A}$, and $\sigma_{E}$ with height. Where $v_{1}$ is the value of the variable at height $z_{1}$, and $V_{2}$ is the value of the variable at $z_{2}, B_{V}$ is an exponent which is a function of stability conditions. Table 1 gives values of $B_{u}, B_{\sigma_{A}}$, and $B_{\sigma_{F}}$ for seven stability conditions obtained by Pendergast [1976 ] for the WJBF-TV tower.

A 1 inear interpolation scheme of the form

$$
V_{2}=V_{1}+\left(z_{2}-z_{1}\right) C
$$

is used to adjust wind direction and temperature, where the notation is as above and $\mathrm{C}$ is a constant which is a function of stability. The values of $\mathrm{C}$ for temperature $\left(\mathrm{C}_{\mathrm{T}}\right)$ and wind direction $\left(C_{D}\right)$ are given in Table 2. The expected error in temperature, $\mathrm{E}_{\mathrm{T}}$, is assumed to be about $5^{\circ} \mathrm{C}$. This is much larger than the standard deviation in temperature at any one level, but the crude method used to extrapolate temperatures to other levels has large uncertainties. The expected error in wind direction is assumed to be $E_{D}$ as described above.

TABLE 1

Power Law Exponents for $u, \sigma_{A}$, and $\sigma_{E}$ at SRP

$\begin{array}{llllll}\text { Stability } & \begin{array}{l}\text { Pasquizz } \\ \text { Stability class }\end{array} & \underline{P} & \underline{B_{u}} & { }_{\sigma_{A}} & { }^{B_{\sigma_{E}}} \\ \sigma_{\mathrm{A}} \geqslant 23 & \text { Extremely unstable } & 1 & .08 & -.06 & .02 \\ 18 \leqslant \sigma_{\mathrm{A}}<23 & \text { Moderately unstable } & 2 & .10 & -.15 & .04 \\ 13 \leqslant \sigma_{\mathrm{A}}<18 & \text { Slightly unstable } & 3 & .11 & -.17 & .01 \\ 8 \leqslant \sigma_{\mathrm{A}}<13 & \text { Near neutral } & 4 & .18 & -.23 & -.14 \\ 4 \leqslant \sigma_{\mathrm{A}}<8 & \text { Slightly stable } & 5 & .31 & -.38 & -.31 \\ 2 \leqslant \sigma_{\mathrm{A}}<4 & \text { Moderately stable } & 6 & .42 & -.53 & -.49 \\ \sigma_{\mathrm{A}}<2 & \text { Extremely stable } & 7 & .42 & -.53 & -.49\end{array}$




\section{TABLE 2}

Linear Change of Temperature and Wind Direction at SRP After Safety Guide 23 and Pasquill [1964]

\begin{tabular}{|c|c|c|}
\hline Stability class & $C_{T}\left(\frac{{ }^{\circ} \mathrm{C}}{100 \mathrm{~m}}\right)$ & $C_{D}\left(\frac{d e g}{100 m}\right)$ \\
\hline 1 & -1.9 & 5 \\
\hline 2 & -1.8 & 10 \\
\hline 3 & -1.6 & 15 \\
\hline 4 & -1.0 & 20 \\
\hline 5 & 0.5 & 25 \\
\hline 6 & 2.75 & 35 \\
\hline 7 & 4.0 & 35 \\
\hline
\end{tabular}

\section{Additional Features}

Some additional features of the quality control code incorporate meteorological data collected at nearby Bush Field, Augusta, GA. This option of the code assumes that the Bush Field adjusted wind speed, direction, and stability conditions (calculated using the Turner 1961 method) are valid. These values provide a basis for quality control of the SRP data. For example, in the event that all SRP towers are inoperative, the resulting "SRP" winds would be the adjusted Bush Field values. This option must be used with caution because significant differences exist in instrumentation, siting, and averaging time between the Bush Field and the SRP data.

A last feature of the code can be used to assure time continuity of the quality-controlled data. This is implemented by including the last time period's observation as if it were a quality-controlled observation for the present time. Just as for the Bush Field case above, if all data for a time period were in error, the SRP data would be identical to the data for the previous time period. 


\section{REFERENCES}

1. Pendergast, M. M. Turbulence Statistics as a Function of Sampling Period. Report No. DP-1455. E. I. du Pont de Nemours \& Co., Savannah River Laboratory, Aiken, SC (1976).

2. Slade, D. Meteorology and Atomic Energy. Report No. TID-24190. Clearinghouse for Federal Scientific and Technical Information, U. S. Department of Commerce, Springfield, VA (1968).

3. Pasquil1, F. "The Estimation of the Dispersion of Wind Vane Material." Meteorologist Magazine, 90, 33-40 (1963).

4. Turner, D. B. "Relationship Between 24-hr Mean Air Quality Measurements and Meteorological Factors in Nashville, TN." Joumal Air Pollution Control Association, 11, 483-489 (1961).

5. Weber, A. H., Irwin, J. S., Kahler, J. P., and Petersen, W. B. "Atmospheric Turbulence Properties in the Lowest 300 Meters." USEPA Report No. EPA-600/4-75-004, U.S. Environmental Protection Agency, Washington, DC (1975). 